\title{
The Neurobiology of NoCiceptive ANd Anti-noCiceptive Systems
}

\author{
James Giordano, PhD
}

Pain is both a sensory event of the peripheral and central nervous systems and an experience that arises from, and reciprocally can affect processes of higher consciousness. Alterations in peripheral and central neuraxes can lead to sensitization, structural modification and long-term potentiation that can overcome modulatory influence(s) and change the non-linear adaptability of these systems to a progressively linear, patholog-

Pain exists as both a sensory event of the peripheral and central nervous systems and as a profound phenomenological experience that affects the processes of consciousness and therefore, expression and definition of the "self" of those individuals in pain. Traumatically acute and prolonged durable pain can produce functional changes in peripheral and central nociceptive neurons that may lead to sensitization, structural modification, and long-term potentiation. We have gone beyond simply examining the anatomy and chemistry of pain, and have begun to focus on the relationships between molecular changes and the effects these incur as we ascend the neurological axis to confront the brain-mind interface. The effects of durable pain change the adaptive, non-linearity of the sensory and cognitive neural systems to a progressively linear, pathologic state that becomes increasing-

From: Georgetown University Medical Center, Washington, DC

Address Correspondence:

James Giordano, PhD, Georgetown University Medical Center, 1500 Reservoir Rd., Washington, DC 20057

E-mail: Gsynapse22@aol.com

Funding: This work was supported in part by funding from the Institute for Integrative Medical Research, Ethics and Policy and the Moody Foundation, Houston, TX.

Conflict of Interest: None

Manuscript received on $6 / 1 / 2005$

Revision submitted on 6/20/2005

Accepted for publication on $7 / 3 / 2005$ ic state with a diverse constellation of clinical signs and symptoms.

Recent progress in molecular biology, neurochemistry and neuroanatomy has led to significant advancement in understanding the interactive roles of these heterogeneous systems in mediating and modulating various types of pain. This review concisely provides an overview of the structure and function of these substrates. As we reach the midpoint in a decade marked by pain control and research, such knowledge is critical to further both a more comprehensive appreciation of the phenomenon that is pain, and the development of therapeutic interventions that are innovative and effective.

Keywords: Pain, analgesia, neuroanatomy, neurobiology, neuropharmacology

ly dysfunctional and evokes an expanded constellation of clinical manifestations. This review provides an overview of nociceptive and anti-nociceptive systems that afford insight to substrates that are relevant to clinical intervention(s).

\section{Nociceptive Systems}

\section{Transduction of Noxious Stimuli}

In cutaneous, muscle and visceral tissues, transduction of high threshold (noxious) chemical, mechanical and/ or thermal stimuli to electrophysiological activity occurs at specialized free nerve endings of nocisponsive primary afferents. The transductive mechanism involves activation of cationic channels on free nerve endings directly by biophysical properties of the high threshold noxious stimuli and indirectly by chemical changes in the local micro and macro environment produced by such stimuli, and trauma. Thermal nociceptive transduction is mediated by vanilloid-type receptor-cationic channel(s). The vanilloid receptor-1 (TRPV1) responds to noxious heat $\left(>45^{\circ} \mathrm{C}\right)$ and is capsaicin-sensitive. A second type, the vanilloid receptor-like protein-1 (TRPV2) is capsaicin-insensitive and has a higher thermal threshold of approximately $52^{\circ} \mathrm{C}$.The cold- and menthol- receptor-1 (CMR-1/T8) responds to noxious cold $\left(8^{\circ}-25^{\circ} \mathrm{C}\right)$ and menthol. Both hot-and cold-responsive channels react to thermal change by increasing mono- or divalent cationic flux, leading to membrane depolarization and transduction $(1,2)$.

High threshold compressive or tensile mechanical input engages a non-specific cationic channel by distorting collagenous bridging elements between the membrane of free nerve endings and the surrounding tissue matrix. With mechanical alteration of the receptive field of the neural membrane, changes in channel configuration produce inward $\mathrm{Na}^{+}, \mathrm{K}^{+}$ and/or $\mathrm{Ca}^{++}$currents (3). The nociceptor potential is graded, membrane polarity is intensity- and temporally- dependent. At the $\mathrm{Na}^{+}$threshold, voltage-gated $\mathrm{Na}^{+}$channels are activated, propagating depolarization along the nociceptor membrane. Both $\mathrm{Na}^{+}$and $\mathrm{Ca}^{++}$influx lead to the release of $\mathrm{Ca}^{++}$from intracellular stores, increasing $\mathrm{Ca}^{++}$concentrations to engage signaling systems mediating shortterm functional changes that may lead to leftward shifts in nociceptive threshold. Also, long term changes in $\mathrm{Ca}^{++}$-dependent intracellular signaling mechanisms alter early and late-phase transcription to modify translation, and protein synthesis alters neuronal microstructure. Taken together these changes contribute to sensitization of peripheral afferents (4).

High threshold input can disrupt neural and non-neural membranes to release fatty acids as well as mono and divalent cations. Liberated free fatty acids are catalyzed by phospholipase-A2 to pro- 
duce arachidonic acid; increased concentration of arachidonic acid induces the isoenzyme cyclo-oxygenase-2 (COX-2) to accelerate prostaglandin formation, with "downstream" production of prostaglandin synthase-generated prostaglandinE2. Prostaglandin-E2 acts at PGE-2 receptors on nociceptors to increase adenyl cyclase, elevating cyclic adenosine monophosphate (cAMP) to engage specific pro-

Table 1. Algogenic stimuli and substrate(s) mediating transduction

\begin{tabular}{|c|c|}
\hline $\mathrm{H}+$ ion & $\begin{array}{l}\text { TRPV1/ VR1 receptor channel } \\
\mathrm{Na}+\mathrm{Ca}++ \text { influx }\end{array}$ \\
\hline Protons & $\begin{array}{l}\text { Acid- sensitive ion channel (ASIC) } \\
\qquad \mathrm{Na}+\text { influx }\end{array}$ \\
\hline Noxious $\mathrm{H}$ & $\begin{array}{l}\text { eat }>45^{\circ} \mathrm{C} \text { (and capsaicin) } \\
\text { TRPV1/VR1 } \\
\left.\text { eat }>53^{\circ} \mathrm{C} \text { (capsaicin insensitive }\right) \\
\text { TRPV2 } \\
\quad \mathrm{Na}+, \mathrm{Ca}++ \text { influx }\end{array}$ \\
\hline Noxious Cc & $\begin{array}{l}\mathrm{old}^{\circ}-\mathbf{2 5 ^ { \circ } \mathrm { C }} \text { (and menthol) } \\
\mathrm{CMR} 1 / \operatorname{trpM} 8 \\
\mathrm{Na}+, \mathrm{K}+, \mathrm{Ca}++ \text { influx }\end{array}$ \\
\hline Mechanica & $\begin{array}{l}\text { Distortion } \\
\text { Non-selective cation channel } \\
\qquad \mathrm{Na}+, \mathrm{K}+, \mathrm{Ca}++ \text { influx }\end{array}$ \\
\hline BDNF & $\begin{array}{l}\text { Trk-B receptor } \\
\quad \text { MAPK activation- transcription effects }\end{array}$ \\
\hline Prostaglan & $\begin{array}{l}\text { din- E2 } \\
\text { Prostanoid receptor } \\
\quad \text { Metabotropic activation of protein kinase }\end{array}$ \\
\hline Serotonin & 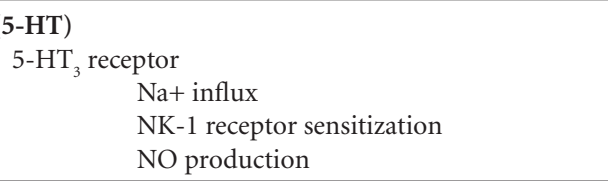 \\
\hline Adenosine & $\begin{array}{l}\text { A2 purinoreceptor } \\
\text { Sensitization of } \mathrm{Na}+\text { channels }\end{array}$ \\
\hline ATP & $\begin{array}{l}\mathrm{PTX}_{3} \text { receptor } \\
\quad \text { Sensitization of } \mathrm{Na}+\text { channels }\end{array}$ \\
\hline Glutamate & $\begin{array}{l}\text { AMPA receptor } \\
\text { NMDA receptor (GluR) } \\
\text { mGlu receptor } \\
\qquad \begin{array}{l}\text { Na+ influx } \\
\text { Ca++ influx } \\
\text { Phospholipase-C -induced rise in } \\
\text { intracellular Ca++ Protein kinase-C } \\
\text { phosphorylation/ sensitization of trk-B }\end{array}\end{array}$ \\
\hline Bradykinin & $\begin{array}{l}\text { Bradykinin B2 receptor } \\
\text { Cationic influx }\end{array}$ \\
\hline
\end{tabular}

Transmission from the Periphery to the Spinal Cord

Upon transduction of the high threshold stimuli, the nociceptive signal is transmitted by primary nociceptive afferents via $\mathrm{Na}^{+}$- dependent depolarization mediated by several isoforms of $\mathrm{Na}^{+}$channels, most notably the nociceptor-specific $\mathrm{Na}_{\mathrm{v}} 1.8$ and $\mathrm{Na}_{\mathrm{v}} 1.9$ channels. Under normal conditions the majority of these channels are of the tetrodotoxin (TTX)sensitive type, however, neural insult, inflammation, and exposure to algogenic substances cause increased expression of a TTX-resistant (TTX-R) isoform, which may subserve lowered threshold $\mathrm{Na}^{+}$conductance (6).

It is now well known that multiple small-fiber afferents can transmit nociception, based upon their expression of transductive receptors and TTX-R type $\mathrm{Na}^{+}$channels. However, A-delta and Cfibers are still regarded as the principle primary afferents that distinctly subtend noxious input (high threshold mechanical, thermal, polymodal) and their differential activity contributes to the respective sensory qualities of fast and slow pain.

\section{A-Delta Fibers}

Type I and II A-delta fibers are small (1-5 um in diameter) myelinated, rapidly conducting $(5-30 \mathrm{~m} / \mathrm{sec})$ neurons. The conduction rate is correlated to the initial sensation of pain, "first pain," as sharp, localized and subjectively punctuate. A-delta fibers have small receptive fields and specific high threshold ion channels that are activated by high intensity thermal or mechanical input. Type II A-delta thermosponsive fibers are sensitive to capsaicin and respond to noxious heat of 40$45^{\circ} \mathrm{C}$. Response increases with temperature elevation, with asymptotic response at $53^{\circ} \mathrm{C}$. A second population, Type I fibers, are responsive to higher temperatures $\left(52-56^{\circ} \mathrm{C}\right)$ and are capsaicin-insensitive. The responses of these heat-sensitive A-delta fibers subserve the rapid, painful reaction to first exposure of noxious heat and the ability to discriminate thermal (nociceptive) sensation according to intensity. A-delta cold afferents maximally respond to temperatures of approximately $8^{\circ} \mathrm{C}$ and show progressive activity to temperatures less than $25^{\circ} \mathrm{C}(7)$.

Mechanosponsive A-delta fibers respond to high threshold mechanical stimulation such as deep pressure, pinch, and stretch. These fibers may also be sensi- 
tized by, and subsequently co-responsive to (intense) heat. Sensitization of these mechanoreceptive A-delta fibers to thermal stimulation may subserve patterns of hyperalgesia following heat or burn injury (8).

\section{C- and C-like Fibers}

C-fibers constitute the majority of cutaneous nociceptive innervation and are small (0.25-1.5 um diameter), unmyelinated afferents with slower conductance $(0.5-2 \mathrm{~m} / \mathrm{sec})$ and larger receptive fields than A-delta fibers. These characteristics contribute to "second pain," the poorly-localized burning, gnawing sensation that is qualitatively distinct from "first" or fast pain. C-fibers are polymodal, activated by mechanical, thermal and/ or chemical stimuli. The chemical substances that stimulate C-fibers are products of cell disruption, the inflammatory cascade and immunological mediators (9); free $\mathrm{H}^{+}$sensitizes the TRVP1 vanilloid receptor on C-fiber endings to evoke $\mathrm{Na}^{+}$ and $\mathrm{Ca}^{++}$influx. Protons act at acid-sensitive ion channels to induce inward $\mathrm{Na}^{+}$ current. ATP and ATP-derived adenosine acts at $\mathrm{PTX}_{3}$ and $\mathrm{A}_{2}$ purinoreceptors, respectively to sensitize $\mathrm{Na}^{+}$channels, increase $\mathrm{Na}^{+}$conductance and evoke depolarization. Such chemical stimulation may occur following thermal or mechanical insult and produces a sensitizing leftward shift in C-fiber response threshold. These sensitized C-fibers can be activated by non-noxious, low intensity stimulation that accounts, in part, for the second pain and/or hyperalgesia as a consequence of inflammation (10).

C-fibers, and some A-delta fibers also innervate the intrafibril matrix and areas proximal to the vascular walls of muscle tissue, as well as musculo-tendonous insertion zones and tendons. Polymodal Cafferents respond to both direct mechanical distortion excessive stretch, torsion or hyper-compression - and to substances resulting from prolonged anaerobic metabolism and ischemia. Muscular C-fibers are activated by $\mathrm{H}^{+}$ions of the acidic post-metabolic environment and by inflammatory mediators following exercise induced micro- or macro-trauma, microedema and heat. The stretch reflex does not normally activate intramuscular C-fibers, however, under ischemic conditions C-fibers may be sensitized to respond to myofibril contraction and stretch within the physiologic range. Ischemia increases the concentration of free adenosine which activates $A_{2}$ receptor-linked G-proteinmodulation of $\mathrm{Na}^{+}$channel threshold(s). Such sensitization appears to subserve the diffuse pain that occurs during passive and active articulation of skeletal muscle that has been over-exerted or subjected to mechanical or ischemic insult $(11,12)$.

There is considerable C-fiber innervation of the viscera, although polymodal A-delta fibers are significantly abundant in the testes, structures surrounding the heart, and a small unmyelinated C-like fiber has been described in the lung parenchyma (13). The nociceptive afferent innervation of visceral structures is more sparse than in cutaneous or muscular tissues; there is also considerable diffusion of visceral afferent input within the spinal dorsal horn. Sensitization by chemical mediators of the inflammatory cascade or sympathetic outflow is required for the sustained firing of the visceral nociceptive afferents necessary to activate second order spinal afferents and transmit the nociceptive signal. The initial sensation and perception of visceral pain is somewhat vague; intensity and localization increase as a function of increased discharge frequency of primary afferents and summated transmission at secondorder spinal neurons. Visceral nociceptive afferents are anatomically co-localized with somatocutaneous afferents in the entry zone of the dorsal root ganglia and within afferent synaptic fields of the dorsal horn. Increased transmission of visceral neurons at the dorsal root and horn zones where their input overlaps with somatocutaneous afferents causes signal convergence at second-order neurons and may subserve the somatic referral pattern that frequently accompanies visceral pain (14).

Also, there is often co-localization of visceral nociceptive and sympathetic (efferent) neurons. Stimulation of sympathetic fibers by ephaptic transmission from adjacent nociceptive afferents or by direct co-stimulation of sympathetic nerves following peripheral insult can increase synthesis and membrane expression of high-affinity adrenergic receptors, enhancing peripheral adrenergic sensitivity, sympathetically-maintained pain and peripheral autonomic dysregulation. Noxious stimulation of visceral structures can thus excite sympathetic neurons to induce efferent sympathetic out- flow, producing altered autonomic tone and sympathetically mediated hyperalgesia. Sympathetic alterations are also observed in certain cutaneous and muscular pain syndromes (15) and are contributory to the vaso- and sudomotor characteristics of complex regional pain syndromes (CRPS) (Table 2).

\section{The Neurochemical Basis of Pain Transmission in the Dorsal Horn}

The majority of nociceptive primary afferent fibers project to the superficial dorsal horn, although a small number project to the ventral spinal cord. In the dorsal horn, A-delta and C-fibers synapse upon second order spinal neurons in laminae I, II, IIa, and V, from which originate the ascending nociceptive pathways. A-delta fibers terminate in laminae I, II and IIa; C-fibers terminate laminae II, IIa and V.

Glutamate is the principal excitatory transmitter at the synapse between primary afferent nociceptors and dorsal horn cells. Glutamate initially binds to the alpha-amino-3-hydroxy-5-methyl-isoxazole-4 propionic acid (AMPA) receptor. Glutamate-activation of the AMPA receptor induces a ligand-gated $\mathrm{Na}^{+}$current to produce rapid depolarization. Sustained $\mathrm{Na}+$ flux activates the N-methyl-D-aspartate (NMDA) receptor, by voltage-dependent displacement of $\mathrm{Mg}+$ from the NMDA receptor, releasing it from an inaccessible configuration to an active site with subsequent high affinity for glutamate.

The AMPA receptor is a heteromeric composite of multiple potential glutamate binding sites (GluR) that regulate a fast-on, slow-off, $\mathrm{Ca}^{++}$ionophore. Additionally, one or more of the eight metabotropic, G-protein-coupled glutamate receptors (mGluR) exist in nociceptive neurons. Activation of the mGluR induces a specific phospholipase- $C$ to engage inositol triphosphate (IP3)-mediated release of $\mathrm{Ca}^{++}$from intracellular stores. Increased intracellular $\mathrm{Ca}^{++}$activates $\mathrm{Ca}^{++}$-sensitive protein kinase-C (PKC) to phosphorylate inactive and sub-membrane fractions of AMPA, NMDA, GluR and mGlu receptors, altering the sensitivity of these receptors and affecting their shuttling to active zones on the neural membrane. Metabotropic mGluRs can also engage diacylglycerol (DAG) to produce PKC-mediated phosphorylation of the tyrosine kinase-B (trkB) receptor for brain-derived 
Table 2. Neurochemical and physiologic properties of primary nociceptive afferents

\begin{tabular}{|c|c|c|}
\hline Type & A-DeLta & C-FIBER \\
\hline Anatomy & $\begin{array}{c}\text { Free endings } \\
\text { Myelinated } \\
1-5 \mu \mathrm{m} \text { fiber diameter } \\
\text { Punctate fields }\end{array}$ & $\begin{array}{c}\text { Free endings } \\
\text { Un-myelinated } \\
0.5-1.5 \mu \mathrm{m} \text { fiber diameter } \\
\text { Diffuse receptive fields }\end{array}$ \\
\hline Stimulus & $\begin{array}{l}\text { High threshold } \\
\text { Mechanical } \\
\text { Thermal } \\
\left(>45^{\circ},>53^{\circ} \mathrm{C}\right) \\
\left(<25^{\circ} \mathrm{C}\right)\end{array}$ & $\begin{array}{l}\text { High threshold } \\
\text { Mechanical } \\
\text { Thermal } \\
\text { Chemical } \\
\text { Polymodal }\end{array}$ \\
\hline $\begin{array}{l}\text { Physiologic } \\
\text { Properties }\end{array}$ & $\begin{array}{c}\text { Fast } \\
10-30 \mathrm{~m} / \mathrm{sec} \text { conduction } \\
\text { First pain } \\
\text { Well localized }\end{array}$ & $\begin{array}{c}\text { Slow } \\
0.5-2 \mathrm{~m} / \mathrm{sec} \text { conduction } \\
\text { Second pain } \\
\text { Poorly localized } \\
\text { Sensitized. Cross-Sensitized }\end{array}$ \\
\hline Neuro Chemistry & $\begin{array}{l}\text { Glutamate } \\
\text { Subs- P } \\
\text { CGRP } \\
\text { VIP } \\
\text { - Post-synaptic activation of } \\
\text { AMPA receptors } \\
\text { - Short-term NK-1 receptor } \\
\text { activation }\end{array}$ & $\begin{array}{l}\text { Glutamate } \\
\text { Subs- P } \\
\text { CGRP } \\
\text { - Post- synaptic activation of NMDA } \\
\text { receptors } \\
\text { - Potentiated NK- 1 receptor } \\
\text { activation } \\
\text { - May induce neural plasticity }\end{array}$ \\
\hline
\end{tabular}

neurotrophic factor (BDNF). BDNF is produced and released by primary nociceptive afferent; it acts at post-synaptic trkB-receptors to initiate mitogen-activated protein kinase (MAPK), affects gene transcription and induces translational change and altered expression of synaptic membrane- and receptor-associated proteins $(16,17)$

These mechanisms of receptor dynamics may alter the synaptic "state" and subserve acute and intermediate sensitization of second-order afferents. Prolonged activation of newly synthesized glutamate receptors can affect genomic elements to produce durable change in the neuronal microstructure leading to plasticity and long-term potentiation (LTP) of nociceptive circuits and long-term depression (LTD) of pain modulating circuitry (Fig. 1)

High intensity or prolonged C-fiber activity causes the release of the tachykinin, substance-P (subs-P). Post-synaptically, subs-P initially binds to neurokinin-2 (NK-2) receptors, and subsequently to high affinity NK-1 receptors that are sensitive to lower subs- $\mathrm{P}$ concentrations. Subs-P acts at NK-1 receptors to induce a G-protein-meditated depolarization and DAG-dependent activation of protein ki- nase (PK)-A and PK-C to phosphorylate NMDA and mGlu receptors and elevate intracellular $\mathrm{Ca}^{++}$. Calcium-dependent phosphorylation of nuclear transcription factors engages the proto-oncogenes $c$-fos, $c$-jun and Krox-24 to produce translational and post-translational protein products that further alter the function and synaptic microstructure of cells receiving and transmitting nociceptive input $(18,19)$.

Sensitized C-fiber afferents retrogradely release subs- $\mathrm{P}$, acting at NK-1 receptors on mast cells to induce de-granulation of the pro-inflammatory chemicals histamine and serotonin (5-HT). C-afferents also release calcitonin gene related peptide (CGRP); CGRP activates the induced isoenzyme nitric oxide synthase (iNOS) to enhance production of nitric oxide (NO) and increase peripheral vasodilation (10). The effects of histamine, 5-HT, subs-P, and CGRP are synergistic. In peripheral tissue(s), free 5 - $\mathrm{HT}$ acts at 5-HT3 receptors on C-fiber terminals to directly induce a fast $\mathrm{Na}^{+}$-dependent depolarization, sensitizes NK-1 receptors to subs-P, and evokes co-release of CGRP to increase iNO production, thereby perpetuating the cycle of C-fiber-mediated neurogenic inflammation and pain $(20,21)$.

\section{Dorsal Horn Afferents}

In the dorsal horn, A-delta and Cfibers synapse upon WDR and NS neurons that spatially and temporally transform afferent input(s). While a small percentage of the axons from these neurons ascend ipsilaterally within the cord, most project contralaterally to form the spinothalamic tract(s) (STT) and ascend in the anterolateral quadrant.

WDR neurons are found in progressively increasing numbers from laminae I, II, V to VI. These neurons receive input both from low threshold A-alpha and A-beta non-nociceptive afferents as well as A-delta and C-fibers, with the majority of nociceptive fiber input in lamina V. The WDR units of laminae I and II are responsive to non-noxious thermal and gentle mechanical input. WDR cells of lamina $\mathrm{V}$ have large receptive fields with limited, discrete areas excited by non-noxious input and broad zones that are highly responsive to high threshold stimulation. These receptive field properties function in stimulus intensity discrimination with different stimulus intensities activating distinct receptive field zones in populations of WDR neurons. The slight phase difference in temporal activation produces differing responses in these groups of WDR cells. As greater numbers of WDR neurons become stimulated there is an increase in both the spatial and temporal summation of their responses, resulting in amplification of the pain signal (22).

Nociceptive specific (NS) neurons are concentrated in laminae I and II, with fewer in lamina V. NS neurons are driven by A-delta and C-fiber input, and have small, center-surround receptive fields in which the central region is excited by high intensity stimuli, while the outer region appears to be inhibited by non-noxious input. These receptive field properties render the NS cell maximally responsive to punctate, high threshold inputs and subserve its function in localization and discrimination of noxious stimuli $(22,23)$.

Both WDR and NS fiber activity contribute to the unique spatial and temporal qualities of pain. NS neurons can remain sensitized following repetitive noxious input and WDR neurons exhibit prolonged after-responses (e.g., "wind-up") generated from the extent and frequency of primary nociceptive afferent input, thus intensifying and continuing nociceptive transmission and sensation(s) (23) (Table 3). 
Spinothalamic Tracts

While a minority of WDR and NS neurons remain ipsilateral and ascend in the ventrolateral quadrant, most project contralaterally to form the STT and ascend in the anterolateral column. Axons from neurons in laminae I and II are somewhat anatomically separate from those of laminae IIa and V, providing a degree of anatomic and functional segregation of the fibers that form the neo-spinothalamic tract (NSTT) and paleo-spino-

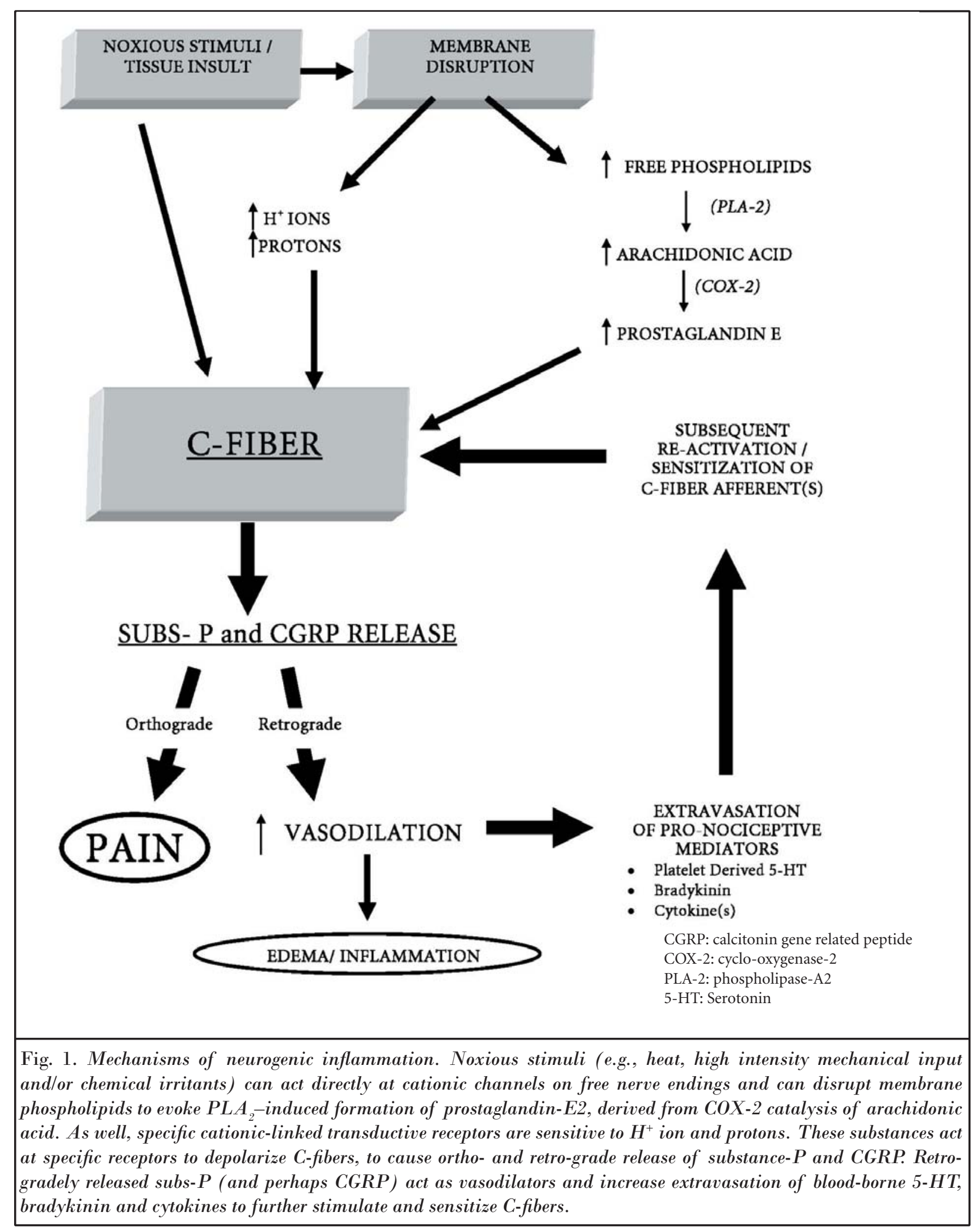


Table 3. Anatomic and physiologic properties of second order afferents

\begin{tabular}{|c|}
\hline $\begin{array}{l}\text { Nociceptive Specific (NS) Neurons } \\
\\
\text { - } \quad \text { Primarily localized in laminae I, II } \\
\text { - } \quad \text { Specive A-delta and C-fiber input } \\
\text { - } \quad \text { Punctate receptive fields } \\
\quad \text { Spatially and temporally summate inputs }\end{array}$ \\
\hline $\begin{array}{l}\text { Wide Dynamic Range (WDR) Neurons } \\
\\
\text { - } \quad \text { Greater numbers in deeper laminae (V,VI) } \\
\text { - } \quad \text { Receive both nociceptor and non-nociceptor inputs } \\
\text { - } \quad \text { Broad receptive fields to poly-synaptic input } \\
\text { - } \quad \text { Spatially and temporally summate } \\
\text { - } \quad \text { Capable of after-discharges (wind-up) }\end{array}$ \\
\hline
\end{tabular}

thalamic tract (PSTT), respectively. The NSTT and PSTT are both relatively specific for pain transmission, yet there are distinctions in the type of nociceptive information conveyed along these pathways. The NSTT is composed of NS fibers from laminae I that project to the parabrachial nucleus and fibers from laminae I and II that terminate in the ventroposterior lateral (VPL) nucleus of the thalamus. The parabrachial projection subserves arousal and autonomic responses to pain via secondary connections to hypothalamic and amygdalar neuraxes, while VPL thalamic projections subtend transmission of stimulus modality and localization, although this is in no way exclusive to other stimulus parameters (24).

The PSTT is predominantly comprised of axons of WDR neurons from laminae IIa and V, with only a smaller number of constituent NS fibers. The heterogeneous response characteristics of WDR cells to noxious and non-noxious input contributes to the transmission of some non-nociceptive signals by the PSTT. WDR neurons progressively summate after-responses to nociceptive input that supersede weaker volleys driven by non-nociceptive afferent activity. These properties contribute to stimulus intensity discrimination and to the characteristic "mixed" sensations that frequently accompany "second" and persistent pain such as ache, itch, tingling, etc. (25).

The PSTT projects to the parabrachial nucleus and to structures of the rostroventral medulla, caudal pons and midbrain that subserve bulbospinal pain modulation and centrifugal analgesia.
Spinoreticular pathways project to the serotonergic raphe nuclei and noradrenergic magnocellular nuclei of the rostroventral medulla and caudal pons, respectively. Spinotectal pathways project to the periaqueductal and periventricular gray (PAG/PVG) regions of the midbrain. Ascending projections from these sites link spinal and cortico-limbic neuraxes to mediate perceptual, cognitive and emotional aspects of pain. Thalamic targets of the PSTT are more diffuse, with projections to the centro-median parafascicular complex, intralaminar, laterodorsal and mediodorsal nuclei $(25,26)$.

\section{Brainstem Systems}

Specific cells of the brainstem (i.e., "on," "off" and "neutral" cells) are differentially responsive to PSTT input driven by noxious stimulation. "On" cells are excited by nociceptive input from the PSTT and engage parabrachial, hypothalamic, cingulate, insular and septo-hippocampal pathways, subserving arousal and aversive reactions to pain. Some 5-HT neurons of the raphe nucleus may be "on" cells that function in descending bulbospinal analgesia, and may participate in nociceptive facilitation that occurs in chronic inflammation and neuropathic pain states. "Off" cells hyperpolarize in response to PSTT activation and reduce the transmission of nociceptive volleys at the brainstem. The summative actions of these cells are dependent upon the duration, intensity, and type of noxious input contributing to inhibitory or facilitatory patterns of pain modulation (27).

PSTT projections to distinct nu- clei of the brainstem possibly subserve some stimulus-specific involvement of descending serotonin (5-HT) and norepinephrine (NE) systems. Thermal and chemical/inflammatory pain appears to engage raphe-spinal 5-HT circuitry, while mechanical input produces greater activation of magnocellular-spinal NE neuraxes. It is not clear whether these distinctions are truly stimulus-specific or reflect different bulbospinal responses to stimulus intensity, duration, or both (28). While it is well known that these systems function in pain inhibition (vide infra), recent evidence supports the involvement of the raphe-spinal 5-HT system in pain facilitation (29).

Serotonin acts through heterogeneous 5-HT1, 5-HT2 and 5-HT3 found post-synaptically on primary and second-order afferents, and interneurons in superficial and deep layers of the dorsal horn. The action of 5-HT at post-synaptic 5-HT1 and/or 5-HT2 receptors directly inhibits primary and/or second-order cells to produce analgesia. Raphe-spinal 5-HT can also indirectly modulate pain by acting at excitatory 5-HT3 receptors on inhibitory interneurons to evoke the release of inhibitory neurotransmitters such as GABA, glycine, enkephalin, and dynorphin. Under normal conditions and perhaps during acute pain, there is limited expression of 5-HT3 receptors and a relative "tone" of excitation and inhibition is maintained within the pool of spinal nociceptive neurons. However, more durable, intense pain, as well as peripheral inflammation and neural insult, appear to evoke up-regulation of 5-HT3 sites on both interneurons and small-diameter, nociceptive afferents of the superficial lamina. In the former case, this may represent 5-HT3 receptor sensitization to progressively rising concentration of 5-HT released from the terminals of descending raphe-spinal neurons in response to direct PSTT stimulation (30).

Expression of 5-HT3 receptors on lamina I nociceptive cells appears to involve an NK-1-receptor-dependent mechanism in which subs-P activation of NK1 receptors initiates transcription, translation and/or commitment of a sub-membrane fraction of 5-HT3 receptors that then mediate an excitatory response to raphe-spinal 5-HT. Hyper-excitation of interneurons results in depletive turnover of inhibitory neurotransmitters; 5-HT3 receptor-mediated excitation of nociceptive 
cells of the cord "reverse" the characteristic inhibitory effect of the raphe-spinal 5HT system. Taken together, these actions lead to nociceptive facilitation and sensations of pain in excess of the level of organic insult that is often observed in inflammatory, neuropathic or chronic pain states (29).

\section{The Midbrain}

The PSTT projects to and activates the PAG directly via interneurons from the brainstem. The PAG is somatotopically organized such that the posterior PAG receives PSTT fibers of the caudal cord, while PSTT fibers from the rostral cord project to the anterior PAG. In addition to being a primary site of centrifugal pain control, the PAG also subserves afferent processing of the pain signal; projections from the PAG to the hypothalamus and structures of the forebrain such as the septal nuclei and amygdala, elicit arousal and behavioral activation that have aversive affective content and expression (31). These responses function in pain conditioning by activating cognitive circuitry of the mammillo-thalamic tract, anterior thalamic nucleus, cingulatum, and regions of the hippocampus to act in synergy with the reticular system, cingulate gyrus, insula and orbito- and frontal cortices.

\section{The Thalamus}

NSTT neurons project to the caudal ventroposterior lateral nucleus (VPLc) and are arranged in somatotopic columns. Thalamic neurons within these columns retain many of the response characteristics of WDR and NS cells, and summate responses as a function of stimulus frequency and intensity. Spatial and temporal summation prolong thalamic cell firing in excess of the provocative noxious stimulus and the volley time of afferent discharges. Such serial processing of nociceptive input may contribute to the qualitative and quantitative characteristics of pain sensation (32).

The PSTT projects to the intralaminar, dorsal centralis lateralis and mediodorsal nuclei, and the majority of these thalamic neurons are responsive to input from both nociceptive and non-nociceptive cutaneous and visceral afferents. The somatotopic organization of intralaminar neurons is more diffuse, and these cells project to the S-II somatosensory associative cortex, anterior and posterior cingu- late gyrus and amygdala, to synergistically mediate aversive and avoidant responses to pain (Fig. 2) (33).

\section{Thalamo-Cortical Projections and the Afferent Role of the Cortex}

Thalamo-cortical fibers from the VPLc primarily project to the S-I sensory cortex, with a lesser projection to $S$ II. Fibers from the intralaminar, lateral, and medial dorsal nuclei activated by the PSTT project bilaterally to S-II, although a small number project to S-I. Thalamic somatotopic organization is retained in SI, and (albeit somewhat less) in S-II, with cortical regions arranged in vertical dominance columns. Only a small percentage of each column is nociceptive neurons; the majority of nociceptive input from the thalamus is concentrated in deeper layers of the cortical columns, while superficial cortical layers receive non-nociceptive thalamic input. The distribution of input from both non-nociceptive and nociceptive afferents in a given column underlies the cortical "assemblage" of neural signals to create the subjective sensorium (34). The unique qualities of the duration, intensity, and modality of the pain signal reflect progressive transformation of hierarchical afferent input through the contributory neuraxis.

Projections from S-II to the anterior cingulate (via the insula) and to the posterior cingulate play a role in pain sensation and pain-related behavioral responses (e.g., arousal, nocifensive reactions). Projections from the cingulate to hypothalamic nuclei mediate neuroendocrine and autonomic responses to pain and may also engage non-opioid, hormonally-mediated analgesia. Efferent projections from the anterior cingulate to the caudate, putamen, and nucleus accumbens are involved in the motor responses to pain (35).

The involvement of dopaminergic (DA) pathways from both the ventral tegmental area (VTA) and substantia nigra pars compacta $(\mathrm{SNpc})$ have been described in cognitive and motoric dimensions of pain. Acting through heterogeneous post-synaptic DA receptors, this meso-limbic DA loop functions in negative reinforcement emotional and motor conditioning effects to aversive stimuli, and may subserve certain stereotypic behaviors of both acute and chronic pain states (36).

Pathways from the hippocampus, su- bicular complex, entorhinal cortex and posterior cingulum further mediate emotional, memory and expectational domains of pain. The lateral dorsal thalamic nucleus and amygdala, together with efferents from the lateral prefrontal, infero-, medio-temporal and infero-parietal cortices mediate higher order cognitive dimensions such as expectation and associative value of pain $(37,38)$.

Hierarchic neural processing expands nociceptive sense data into consciousness of internal state, external circumstance, memory and affective factors that have both subjective and ontologic meaning to the pain sufferer. Thus, the phenomenologic experience of pain may vary widely for each individual as a result of cortico-limbic processing of complex external and internal stimuli, association(s) to prior circumstance(s) and even socio-cultural contexts. It is likely that "pain" as an experience, is both a sensory event reflecting activation of afferent pathways and a process of consciousness arising from alterations of multiple domains of brain state(s) (Fig. 2).

\section{Anti-nociceptive Systems}

\section{Spinal Pain Modulation}

Inhibitory interneurons in laminae $\mathrm{I}$ and $\mathrm{V}$ of the dorsal horn receive collaterals from A-delta and C-fibers. These interneurons synapse upon primary afferents and second-order WDR and NS cells within a horizontal segment of the cord, although some interneurons project trans-segmentally. The pattern of primary afferent firing can activate these spinal interneurons to exert recurrent inhibition or suppress firing of post-synaptic second-order cells.

These interneurons release GABA, glycine, the opioids dynorphin, leucineand methionine-enkephalin and endogenous cannabinoids. GABA acts at postsynaptic $\mathrm{GABA}_{-\mathrm{A}}$ receptors on primary and second-order afferents to induce a slow, chloride anionic hyperpolarizing current; it acts at post-synaptic GABA $_{-B}$ receptors to metabotropically initiate $\mathrm{K}^{+}-$ mediated hyperpolarization. Dynorphin acts at post-synaptic kappa/OR2 receptors that are negatively coupled to N-type $\mathrm{Ca}^{++}$channels. The dynorphin-activated kappa/OR2 receptor undergoes conformational change, closing the $\mathrm{Ca}^{++}$channel and producing a gradual hyperpolarization. Leu- and met-enkephalin act at both 
delta/OR1 and mu/OR3 opioid receptors to activate G-protein-mediated kinases, phosphorylate $\mathrm{K}^{+}$channels and increase $\mathrm{K}^{+}$influx to produce a hyperpolarizing current. The amino acid glycine may be released or co-released from GABA and dynorphin interneurons. Glycine acts at the glycine receptor, is an ionotropic $\mathrm{Cl}^{-}$ ionophore, and induces membrane hyperpolarization and post-synaptic inhibition (39). Prostaglandins, specifically PGE2 can antagonize the glycine recep-

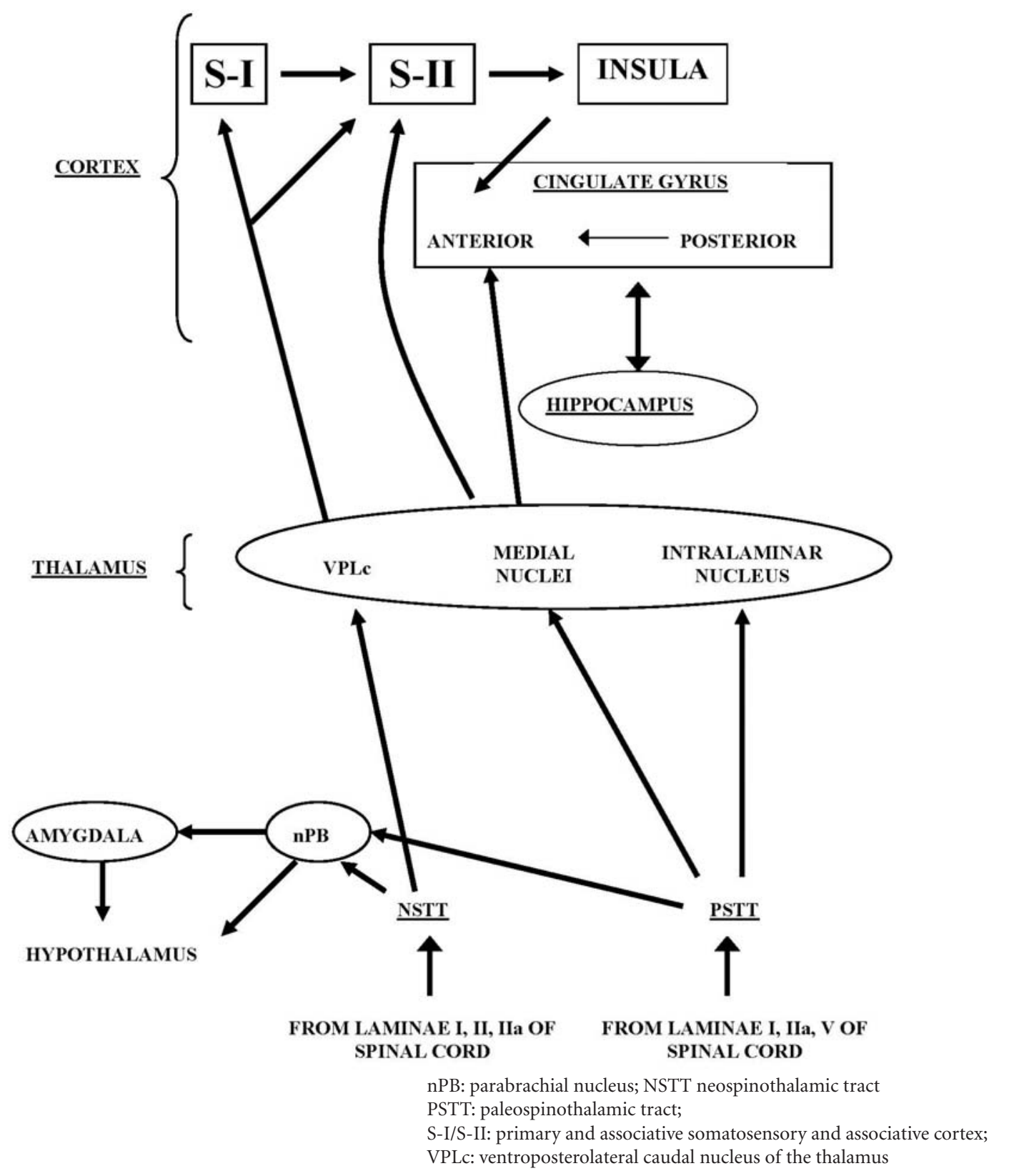

Fig. 2. Schematic of spinothalamic and thalamo-cortical pathways mediating sensory and cognitive dimensions of pain. The PSTT projects to intralaminar and medial thalamic nuclei. Projections from these nuclei to the anterior cingulate gyrus function in affective dimensions of pain. The anterior cingulate also receives input from the posterior cingulate, SII associative cortex and hippocampus. The PSTT projects to the parabrachial nucleus (nPB) to activate the amygdala and hypothalamus, to mediate arousal and autonomic responses to pain. The NSTT projects to the VPLc thalamic nucleus. Thalamocortical pathways from VPLc project to SI and SII to mediate sensory discriminative aspects of pain. SI and SII and the SII-insular-cingulate pathways function in cognitive and emotional dimensions of pain. 
tor, thereby reducing the interneuronal pain modulation and producing a trend toward pain facilitation that is characteristic in neurogenic inflammatory conditions. The endogenous cannabinoids, anandamide and 2-arachadoylglycerol, act at type-1 cannabinoid (CB-1) receptors on second-order neurons in the dorsal root ganglia and superficial laminae, to produce a slow hyperpolarization. Additionally, CB-1 receptors are found in cortical and sub-cortical limbic areas where anandamide and exogenous cannabis act to modulate pain sensation and suppress arousal and aversive behaviors associated with pain. However, it has recently been shown that at higher concentrations may sensitize primary afferent TRPV (vanilloid) receptors and TTX-resistant $\mathrm{Na}^{+}$ channels to facilitate nociceptive responses (40) (Fig. 3).

\section{Bulbospinal Analgesia}

The PSTT projects to the raphe nuclei the sub-groups of the nucleus raphe magnus (NRM) - of the rostroven- tral medulla (RVM) and the magnocellular nuclei (RMC: the nuclei reticularis gigantocellularis and reticularis paragigantocellularis) of the caudal pons/RVM. The NRM and RMC receive both afferent input from the PSTT and efferent input from the PAG and that can drive systems of the brainstem nuclei to produce bulbospinal and/or centrifugal analgesia, respectively (41). Inhibitory and excitatory connections in the brainstem determine the relative participation or co-participation of the NRM and RMC in modulating

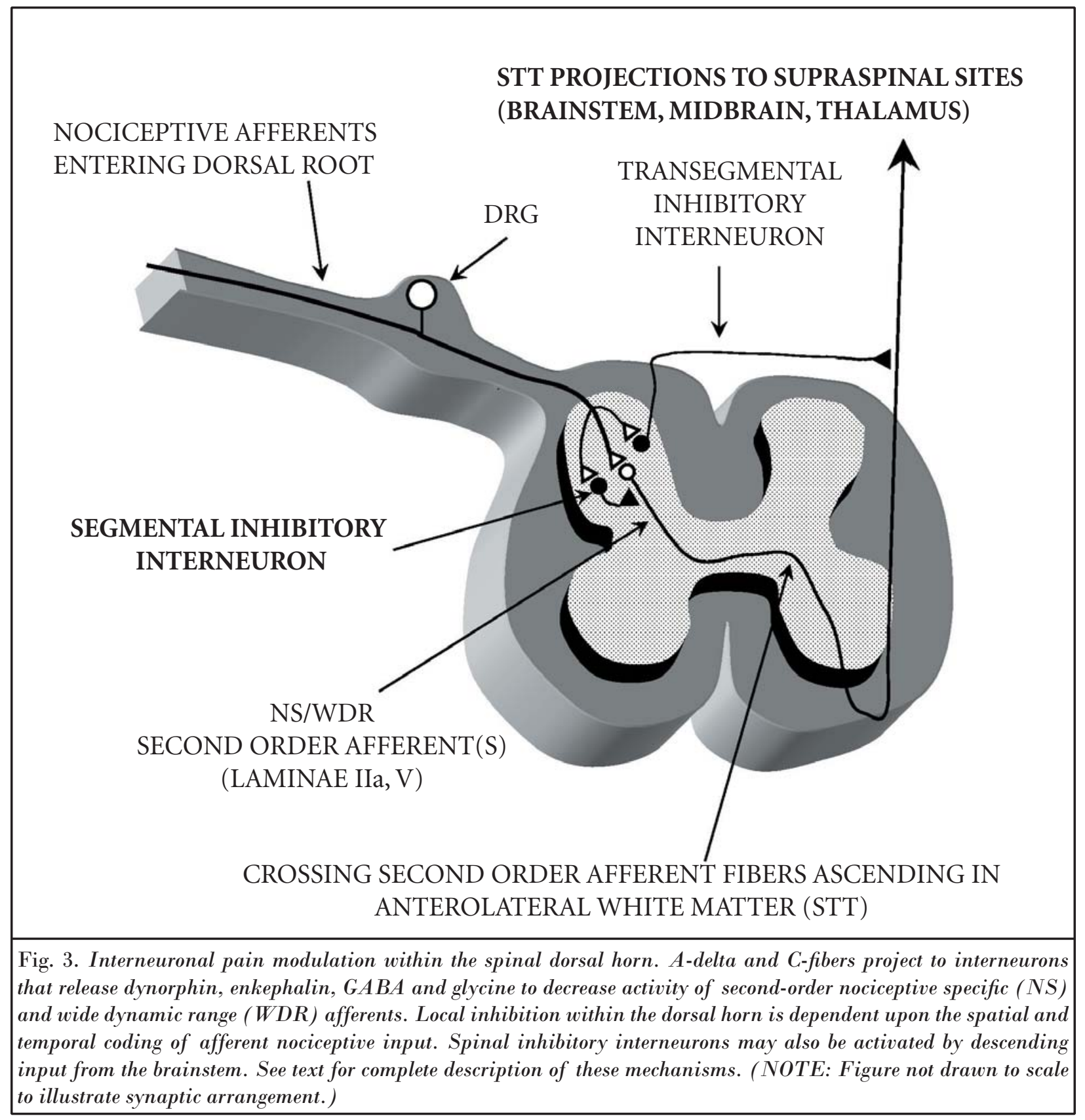


pain of different intensities, duration, and modalities (29).

Projections from the NRM and RMC descend in the spinal dorsolateral funiculi and form polysynaptic contacts with populations of spinal interneurons as well as monosynaptic contact with second-order and primary afferent neurons in laminae I, II and V. The projection of NRM and RMC fibers to groups of thermo-, mechano- or polysponsive afferents and/or their WDR and NS target cells may affect stimulus-specific patterns of anti-nociception mediated by 5 -HT or NE bulbospinal pathways (28).

\section{Midbrain-Centrifugal Analgesia}

Afferent input from the PSTT and efferent projections from the cingulate gyrus, as well as nuclei of the limbic forebrain and hypothalamus activate endorphin-, enkephalin- and orphanin-containing neurons of the PAG. Projections from the PAG to the brainstem are both inhibitory and excitatory. Opioids from the PAG act at post-synaptic mu/OR3 receptors to suppress GABAergic interneurons of the midline brainstem, disinhibiting the tonic and burst activity of descending 5-HT tracts of the raphe-spinal system and descending NE from the RMC (42). In contrast, a glutamate-mediated pathway from the PAG can excite populations of brainstem "on" and "off" cells to directly engage NRM and/or RMC systems to modulate STT activity. The activity of these pathways seems to be reliant upon the intensity of noxious input - milder pain evokes low-level glutamate stimulation of brainstem nuclei while more intense or durable pain engages the PAG in centrifugal suppression of the STT through disinhibition of bulbospinal pathways (41). Additionally, opioids from the PAG/PVG may be released into the cerebrospinal fluid (CSF) and act at populations of delta/OR1 and mu/OR3 receptors on primary, second-order, and interneurons of the spinal cord to inhibit pain transmission $(41,42)$ (Fig. 4, Table 4).

\section{Cortical Pain Modulation}

Neurons of the sensory cortex can directly inhibit thalamo-cortical projections arising from the STT; such cortico-thalamic inhibition of the non-nociceptive medial lemniscal tract can also occur. Such inhibition increases asymptotically with thalamo-cortical input that is rapidly temporally- and spatially-sum- mating, acting as high band-pass filter for nociceptive information. Cortical neurons can also excite both thalamo-cortical and STT fibers to up-modulate "filtered" information. This compensates for different response characteristics between thalamic projections and their target cortical neurons, augments the response-function and enhances the signal:noise ratio of thalamically-driven cortical circuits that function in pain localization and discrimination (43).

Fibers from the frontal, pre-frontal, and orbital cortex can engage limbic circuits of the amygdala, septal nuclei, and hypothalamus to modulate nociception and pain perception. This latter point is of particular interest in that imaging studies have shown the involvement of the lateral prefrontal cortex in placebo and "expectational" analgesia. This site may also activate limbic, or PAG-descending modulatory components, to play a role in the engagement and/or maintenance of diffuse noxious inhibitory pain control (DNIC) produced by peripheral tactile stimulation and/or environmental or behavioral stimuli (44)

\section{Dorsal Column Pain Modulation}

A-beta driven, low threshold mechanosponsive WDR cells can modulate nociceptive activity of the STT. Low intensity mechanical stimuli activate interneurons in laminae II, IIa, and IV that link the fibers of WDR cells of the non-nociceptive dorsal columns with fibers of the STT and produce inhibitory post-synaptic potentials (IPSPs) in STT cells. These IPSPs have a longer duration than the initiating low intensity stimulus, and cause brief, but summative, inhibition of nocisponsive WDR and NS cells of the STT. The dorsal column projects to the medullary nuclei cuneatus and gracilis, decussates at this level, and ascends as the medial lemniscal pathway to project to the VPL, ventromedial, and pulvinar thalamic regions. Low level phasic or high frequency repetitive stimulation of medial lemniscal-thalamic pathways can suppress volleys of nociceptive STT inputs, preventing nociceptive thalamic activity and thalamocortical transmission (45).

There is evidence that A-beta mechanoreceptor/dorsal column stimulation may engage central oxytocin-mediated mechanisms to enhance cortico-limbic and midbrain-centrifugal systems that modulate sensory and perhaps aversive cognitive dimensions of pain, either specifically or as part of DNIC (46). These substrates are partly responsible for the clinical analgesic effects of dorsal column electrostimulation (DCS) and possibly certain manual and tactile therapeutic approaches. Such effects, however, appear to be of relatively short duration and may become ineffective against progressive, increasing pain.

Continuous A-delta and C-fiber activity can functionally and microstructurally remodel the STT and supraspinal nociceptive pathways to potentiate pain transmission, thereby overcoming spinal or thalamic suppression by dorsal column input. Also, C-fiber-mediated neurogenic inflammation induces production of nerve growth factor (NGF) that is released into both peripheral tissue and within the dorsal root ganglia. NGF alters transcription elements in A-beta fibers, causing them to express vanilloid receptors, TTXsensitive and TTX-resistant $\mathrm{Na}^{+}$channels, $\mathrm{Na}^{+}$-sensitive voltage-gated $\mathrm{Ca}^{++}$channels, and produce the peptides subs-P and CGRP, characteristics associated with nociceptive afferent fibers. NGF-exposed Abeta fibers also exhibit synaptic rearrangement, extending collaterals into lamina II and IIa to synapse upon NS and WDR cells (47). Altered physiologic responses to mechanical input and the synaptic connectivities in laminae II and IIa can induce transmission of non-noxious stimuli that are interpreted as painful. This mechanism is responsible both for the loss of dorsal column-mediated pain control and for a component of mechanical allodynia that follows neurogenic inflammation and peripheral neuropathic insult.

\section{Hormonally-Mediated Pain Modulation}

Several hormonal systems have been shown to modulate pain. The hypothalamic-pituitary-adrenal (HPA) axis is of particular note in that both hypothalamic corticotropin releasing factor (CRF) and pituitary adrenocorticotropic hormone $(\mathrm{ACTH})$ produce moderate analgesia. This effect is partially opioid-dependent, suggesting that the corticotropins may both mediate the stress response and induce the synthesis and release of the parent molecule, pro-opiomelanocortin (POMC), leading to facilitated production of ACTH and opioids to further enhance responsivity to stress and pain (48). Pain-induced release of opioids from the PAG and NE from the RMC act at the hy- 


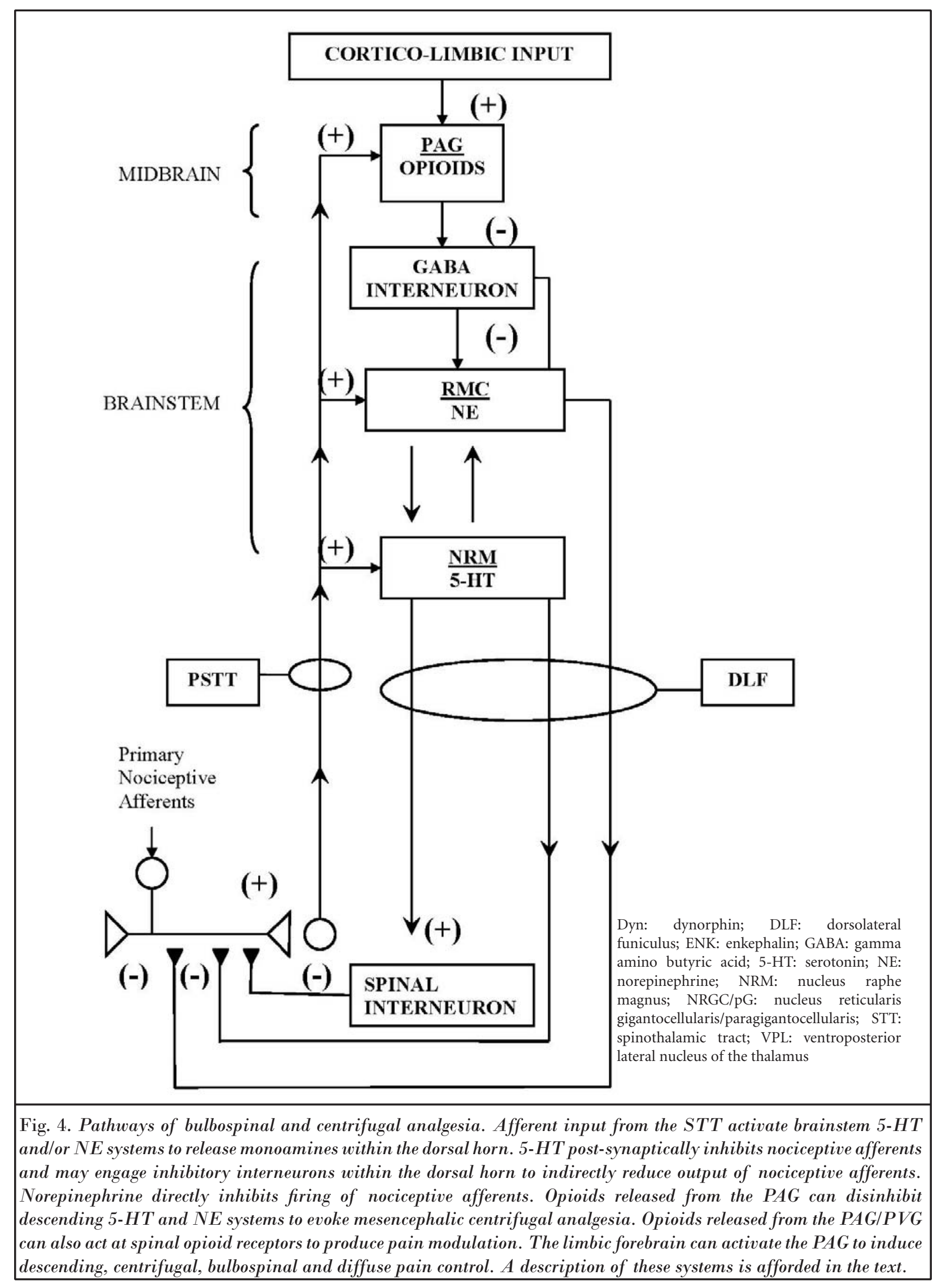


Table 4. Physiologic and pharmacologic properties of spinal and supraspinal pain modulating systems

\begin{tabular}{|c|c|c|}
\hline SYSTEM \& ANATOMY & \multicolumn{2}{|c|}{ ChEMISTRY \& Physiology } \\
\hline & \multicolumn{2}{|r|}{$\begin{array}{l}\text { Acts at } \mathrm{K}^{-} \mathrm{OR}_{2} \text { receptors } \\
\mathrm{G} \text { - protein mediated } \\
\quad \mathrm{K}^{+}, \mathrm{Ca}^{++} \text {mediated hyperpolarization }\end{array}$} \\
\hline$\underline{\text { INTRASPINAL }}$ SEGMENTAL INTERNEURONS & $\begin{array}{l}\text { Leu/ } \\
\text { mettenkephalin: }\end{array}$ & $\begin{array}{l}\text { Acts upon } \mathrm{OR}_{1} \text { and } \mathrm{OR}_{3} \text { receptors } \\
\mathrm{G} \text { - protein mediated } \\
\mathrm{K}^{+} \text {mediated hyperpolarization }\end{array}$ \\
\hline \multirow[t]{3}{*}{$\begin{array}{l}\text { Interneurons in laminae II, } \mathrm{V} \\
\text { - Synaptic contact with recurrent processes of } \\
\text { A-delta fibers }\end{array}$} & GABA & $\begin{array}{l}\text { Acts upon } \mathrm{GABA}_{\mathrm{A}} \text { receptors } \\
\qquad \mathrm{G}^{-} \text {protein mediated } \\
\mathrm{Cl}^{-} \text {mediated hyperpolarization } \\
\text { Acts upon } \mathrm{GABA}_{\mathrm{B}} \text { receptors } \\
\quad \mathrm{G} \text { - protein mediated } \mathrm{K}^{+} \text {hyperpolarization }\end{array}$ \\
\hline & Glycine & $\begin{array}{l}\text { Acts at glycine receptors } \\
\mathrm{Cl}^{-} \text {mediated hyperpolarization }\end{array}$ \\
\hline & Anandamide & $\begin{array}{l}\text { Acts at } \mathrm{CB} 1 \text { receptors } \\
\quad \text { Membrane stabilization/hyperpolarization }\end{array}$ \\
\hline $\begin{array}{l}\text { BULBosPINAL } \\
\text { - Fibers from NRM descend via DLF } \\
\text { - Mono- and polysynaptic contacts with } \\
\text { primary and second-order units of dorsal } \\
\text { horn } \\
\text { - Synapse upon interneurons }\end{array}$ & $\begin{array}{l}\text { A } \\
\text { a }\end{array}$ & $\begin{array}{l}\text { on post-synaptic 5- } \mathrm{HT}_{1 \mathrm{~b}} \text { receptors on (pre-synaptic) primary afferents } \\
\text { ost-synaptic) second-order neurons } \\
\text { G-protein mediated inhibition of cation current(s) } \\
\text { Hyperpolarizing; inhibitory } \\
\text { pon post-synaptic 5-HT } \mathrm{HT}_{3} \text { receptors on GABA and opioid spinal } \\
\text { urons; } \\
\text { Excitatory; evokes release of inhibitory modulators } \\
\text { Up regulation induces pain faciliatation via loss of inhibition/ } \\
\text { excitation }\end{array}$ \\
\hline $\begin{array}{l}\text { BULbOSPINAL } \\
\text { RMC } \\
\text { - Fibers from NRCG/NRpG descend via DLF } \\
\text { Mono- and polysynaptic contacts with } \\
\text { primary and second-order afferents of dorsal } \\
\text { horn }\end{array}$ & \multicolumn{2}{|r|}{$\begin{array}{l}\text { oon post-synaptic alpha }{ }_{2} \text {-receptors on (pre-synaptic) afferents and } \\
\text {-order afferents } \\
\text { G- protein mediated inhibition of cation current(s) } \\
\text { Graded hyperpolarization, inhibitory }\end{array}$} \\
\hline$\underline{\text { MidBRAIN }}$ & $\begin{array}{l}\text { Opioid } \\
\text { Leu/ } \\
\text { met- enkephalin: }\end{array}$ & $\begin{array}{l}\text { Acts at } \mathrm{OR}_{3} \text { and } \mathrm{OR}_{1} \text { receptors } \\
\qquad \mathrm{G} \text { protein mediated } \mathrm{K}^{+} \text {hyperpolarization }\end{array}$ \\
\hline $\begin{array}{l}\text { - Multilevel connections: inputs from } \\
\text { hypothalamus, limbic system, cortex } \\
\text { - Activated by STT } \\
\text { - Polysynaptic contact with brainstem to } \\
\text { disinhibit centrifugal modulatory systems }\end{array}$ & $\begin{array}{l}\text { endorphin } \\
\text { orphanin }\end{array}$ & $\begin{array}{l}\text { Acts at } \mathrm{OR}_{3} \text { receptors } \\
\quad \mathrm{G} \text { protein mediated } \mathrm{K}^{+} \text {hyperpolarization } \\
\text { Acts at } \mathrm{ORL}_{1} \text { receptor } \\
\quad \mathrm{K}^{+} \text {efflux, inhibition of voltage-gated } \mathrm{Ca}^{++} \text {channels }\end{array}$ \\
\hline
\end{tabular}

pothalamus to produce increased levels of induced nitric oxide (iNO). iNO produces vasodilation within the hypothalamic median eminence, increasing CRF and stimulating phasic release of ACTH from the anterior pituitary. Changing levels of ACTH can affect adrenally-mediated stress responses and regulate the pro- duction of POMC-derived opioid pep- the chromaffin cells of the adrenal medultides that have pain- and immuno-mod- la causes the release of adrenal opioids enulatory activity (48).

Acute and durable pain can engage spinal sympathetic innervation and act through the reticular-parabrachial-hypothalamic pathway to induce autonomic responses. Sympathetic stimulation of kephalin and endorphin, plus epinephrine, into the systemic circulation. Adrenal opioids act at mu/OR3 and delta/OR1 opioid receptors of the peripheral nervous system to produce analgesia; changes in immune and metabolic function are mediated by 
the actions of these ligands at $\mathrm{mu}_{3}$ opioid and heterogeneous adrenergic receptors in non-neural tissues such as immunocytes, mast cells, vascular and enteric smooth myocytes, and adipocytes $(49,50)$.

\section{ConCLUSION}

Advances in pain medicine reflect rapid progress in basic, clinical, and more recently, the philosophical domains of research. Systems-mediating nociception and anti-nociception are diverse, and research has just begun to elucidate the implications of such diversity. The theoretical dialectic surrounding conceptualization of peripheral versus central neural sensitization has been reconciled by recognition of nociceptive facilitatory mechanisms that exist throughout the nervous system. Recognition of heterogeneous chemical and molecular mediators of nociception and anti-nociception has fostered revised insight into the complexity of these substrates, and to a realization of the multitude of physiologic effects produced by and subserving pain. By understanding the anatomy, physiology, and neurochemistry of these systems, we may come to appreciate pain both as a neurologic disease process and as an illness phenomenon of the mind, an understanding that will aid in developing more effective research strategies and clinical approaches to expand therapeutic effectiveness against specific types of pain.

\section{ACKNOWLEDGEMENTS}

The author wishes to acknowledge the untiring, cheerful, technical, and graphic artistic assistance of Sherry Loveless in the preparation of this manuscript. As well, the author is appreciative of ongoing intellectual exchange with Drs. Pierre LeRoy and Mark Boswell.

Author Affiliation:

James Giordano, PhD

Research Scholar

Georgetown University Medical Center

1500 Reservoir Road

Washington, DC 20001

and

Fellow, John P. McGovern MD Center

for Health, Humanities and the Humar Spirit

Univ. of Texas Health Sciences Center

Houston, TX

E-mail: Gsynapse22@aol.com

\section{REFERENCES}

1. Caterina MJ, Rosen TA, Tominaga M, Brake AJ, Julius D. A capsaicin-receptor homologue with a high threshold for noxious heat. Nature 1999; 398:436-441.

2. McKemy DD, Neuhausser WM, Julus D. Identification of a cold receptor reveals a general role for TRP channels in thermosensation. Nature 2002; 416:52-58.

3. Woolf CJ. Pain. Moving from symptom control toward mechanism-specific pharmacologic management. Ann Int Med 2004; 140:441-451.

4. Woolf CJ, Salter MW. Neuronal plasticity: increasing the gain in pain. Science 2000; 288:1765-1769.

5. Doubell TP, Mannion R, Woolf CJ. The dorsal horn: State-dependent sensory processing, plasticity and the generation of pain. In Wall PD, Melzack R (eds.) Textbook of Pain, $4^{\text {th }}$ ed. Churchill-Livingstone, Edinburgh, 1999, pp 165-182.

6. Amaya F, Decosterd I, Samad TA, Plumpton C, Tate S, Mannion RJ, Costigan M, Woolf CJ. Diversity of expression of the sensory neuron-specific TTX-resistant voltage-gated sodium ion channels SNS and SNS2. Mol Cell Neurosci 2000; 15:331-342.

7. Kumazawa T, Perl ER. Differential excitation of dorsal horn marginal and substantia gelatinosa neurons by primary afferent units with fine (A-delta and C) fibers. In Zotterman Y (ed.) Sensory Functions of the Skin in Primates with Special Reference to Man. Pergammon Press, Oxford, 1976, pp 67-89.

8. Handwerker HO. The influences of algogenic substances serotonin and bradykinin on the discharge of un-myelinated cutaneous fibers identified as nociceptors. In Bonica J, Albe-Fessard D (eds). Advances in Pain Research and Therapy, Vol. 1, Raven Press, New York, 1976, pp 41-46.

9. Torebjork HE. Afferent C-units responding to mechanical, thermal and chemical stimuli in human non-glabrous skin. Acta Physiol Scand 1974; 92:374-390.

10. Levine JD, Gordon NC, Fields HL. The mechanism of placebo analgesia. Lancet 1978; 2:654-657.

11. Newham DJ, Jones DA. Intramuscular pressure in the painful human biceps. Clin Sci 1985; 69:27P.

12. Mills KR, Newham DJ, Edwards RHT. Force, contraction frequency and energy metabolism as determinants of ischemic muscle pain. Pain 1982; 14:149-154.

13. Coleridge HM, Coleridge JCG, Luck JC. Pulmonary afferent fibres of small diameter stimulated by capsaicin and by hyperinflation of the lungs. J Physiol 1965; 179:248262.

14. Gebhart GF. Visceral pain. In Gebhart GF (ed.) Progress in Pain Research and Management, Vol. 5, IASP Press, Seattle, 1995, pp 351-371.
15. Campbell JN, Meyer RA, Raja SN. Is nociceptor activation by alpha-1 adrenoceptors the culprit in sympathetically-maintained pain? Am Pain Soc J 1992; 1:3-11.

16. Kerr BJ, Bradbury EJ, Bennett DL, Trivedi PM, Dassan P, French J, Shelton DB, McMahon SB, Thompson SW. Brain-derived neurotrophic factor modulates nociceptive sensory inputs and NMDA-evoked responses in the rat spinal cord. J Neurosci 1999; 19:5138-5148.

17. McMahon SB, Bennett DL. Trophic factors and pain. In Wall PD, Melzack R (eds.) Textbook of Pain, $4^{\text {th }}$ ed., Churchill-Livingstone, Edinburg, 1999, pp 105-128.

18. Thompson SWN, Dray A, Urban L. Injuryinduced plasticity of spinal reflex activity: NK-1 neurokinin receptor activation and enhanced A- and C-fiber mediated responses in the rat spinal cord in vitro. J Neurosci 1994; 14:3672-3687.

19. Luo ZD, Chaplan SR, Higuera ES, Sorkin LS, Staudermann KA Williams ME, Yaksh TL. Up-regulation of dorsal root ganglion (alpha)-2-(delta) calcium channel subunit and its correlation with allodynia in spinal nerve-injured rats. J Neurosci 2001; 21: 1868-1875.

20. Cao YQ, Mantyh PW, Carlson EJ, Gillespie AM, Epstein CJ, Basbaum Al. Primary afferent tachykinins are required to experience moderate to intense pain. Nature 1998; 392:390-394.

21. Giordano J, Dyche J. Differential analgesic actions of serotonin 5 - $\mathrm{HT}_{3}$ receptor antagonists in the mouse. Neuropharmacol 1989; 28:423-426.

22. Dubner R. Specialization in nociceptive pathways: Sensory discrimination, sensory modulation and neural connectivity. In Fields HL, Dubner R, Cervero F (eds.) Advances in Pain Research and Therapy, Vol. 9, Raven Press, New York, 1985, pp 111137.

23. Dubner R, Bennett GJ Spinal and trigeminal mechanisms of nociception. Ann Rev Neurosci 1983; 6:381-418.

24. Willis WD. Physiology of the dorsal horn and spinal cord pathways related tom pain. In Beers RF, Bassett EG (eds.) Mechanisms of Pain and Analgesia Compounds. Raven Press, New York, 1979, pp 143-156.

25. Willis WD. Sensory Mechanisms of the Spinal Cord. Plenum Press, New York, 1991.

26. Mancia M, Mariotti M, Caraceni A, Formenti A, Imeri L, Palestini M. Center medianparafascicular thalamic complex and mediodorsal nucleus unitary responses to noxious stimuli and their conditioning by limbic and mesencephalic stimulations. In Tiengo M, Eccles J, Cuello AC, Ottoson $\mathrm{D}$ (eds.) Advances in Pain Research and Therapy, Vol. 10, Raven Press, New York, 1987, pp 17-30.

27. Fields HL, Basbaum Al. Central nervous system mechanisms of pain modulation. In Wall PD, Melzack R (eds.) Textbook of Pain, $4^{\text {th }}$ ed. Churchill Livingstone, Edinburgh, 1999, pp 309-330. 
28. Giordano J, Barr GA. Possible role of spinal 5 -HT in mu- and kappa opioid receptor-mediated analgesia in the developing rat. Devel Brain Res 1988; 33:121-127.

29. Suzuki R, Rygh LJ, Dickenson AH. Bad news from the brain: descending $5-\mathrm{HT}$ pathways that control spinal pain processing. Trends Pharmacol Sci 2004; 25:613 617.

30. Giordano J, Gerstmann H. Patterns of serotonin- and 2-methylserotonin-induced pain may reflect $5-\mathrm{HT} 3$ receptor sensitization. Eur J Pharmacol 2004; 483:267-269.

31. Beitz A. The organization of afferent projections to the midbrain periaqueductal grey of the rat. J Neurosci 1982; 7:133-159.

32. Kenshalo DR, Giesler CJ, Leonard RB, Willis WD. Responses of neurons in primate ventral posterior lateral nucleus to noxious stimuli. / Neurophysiol 1980; 43:15941614 .

33. Willis WD. The Pain System. Karger, Basel, 1985 .

34. Albe-Fessard D. Levante A, Rokyta R. Cortical projections of cat medial thalamic cells. Int J Neurosci 1971; 1:317-338.

35. Devinsky O, Morrell MJ, Vogt BA. Contributions of the anterior cingulate cortex to behavior. Brain 1995; 118:279-306.

36. Cazzullo CL, Gala C. Cognitive and emotional aspects of pain. In Tiengo $\mathrm{M}$, Eccles J, Cuello AC, Ottoson D (eds.) Advances in Pain Research and Therapy, Vol 10, Raven
Press, New York, 1987, pp 255-264.

37. Ploghaus A, Tracey I, Gati JS, Clare S, Menon RS, Matthews PM, Rawlins JN. Dissociating pain from its anticipation in the human brain. Science 1999; 284:1979-1981.

38. Sawamoto N, Honda M, Okada T, Hanakawa T, Kanda M, Fukuyama H, Konishi J, Shibasaki $H$. Expectation of pain enhances responses to non-painful somatosensory stimulation in the anterior cingulate cortex and parietal operculum/posterior insula: an event related functional magnetic resonance imaging study. J Neurosci 2000; 20:7438-7445.

39. Woolf CJ. Pain: Moving from symptom control toward mechanism-specific pharmacologic management. Ann Int Med 2004; 140:441-451.

40. Rice ASC. Cannabinoids and pain. Curr Opin Invest Drugs 2001; 2:399-414.

41. Fields HL, Heinricher MM, Mason P. Neurotransmitters in nociceptive modulatory circuits. Ann Rev Neurosci 1991; 14:219245.

42. Basbaum Al, Fields HL. The origin of descending pathways in the dorsolateral funiculus of the spinal cord of the cat and rat: further studies of the anatomy of pain modulation. J Comp Neurol 1979; 187:513531.

43. Kaas JH. Functional organization of the somatosensory cortex in primates. Ann Anat 1993; 175:509-518.
44. Petrovic P, Kalso E, Petersson KM, Ingvar M. Placebo and opioid analgesia- imaging a shared neuronal network. Science 2002; 295:1737-1740.

45. Boivie J. Anatomical observation on the dorsal column nuclei, their thalamic projection and the cytoarchitecture of some somatosensory thalamic nuclei in the monkey. J Comp Neurol 1980; 178:17-48.

46. Uvnas-Moberg K, Bruzelius G, Alster P, Lundeberg T. The antinociceptive effect of non-noxious sensory stimulation is partly mediated through oxytocinergic mechanisms. Acta Physiol Scand 1993; 149:199204.

47. Lindsay RM, Harmar AJ. Nerve growth factor regulates expression of neuropeptide genes in adult sensory neurons. Nature 1989; 337:362-364.

48. Yang XM, Dunn AJ. Central beta (1)-adrenergic receptors are involved in CRF-induced defensive withdrawal. Pharmacol Biochem Behav 1990; 36:847-851.

49. Stefano GB. Endogenous morphine: A role in wellness medicine. Med Sci Monit 2004; 10:ED5.

50. Stefano GB, Zhu W, Cadet P, Bilfinger TV, Mantione K. Morphine enhances nitric oxide release in the mammalian gastrointestinal tract via the mu (3) opiate receptor subtype: A hormonal role for endogenous morphine. J Physiol Pharmacol 2004; 55: 279-288. 